\title{
Determinación de la acción del azufre nanoencapsulado en liposomas aplicado al cultivo in vitro del hongo Botrytis fabae.
}

\section{Determination of the action of nanoencapsulated sulfur in liposomes applied to the in vitro culture of the Botrytis fabae fungus.}

\author{
Gavilanes Quizhpi (1), Aguirre Yela (1), Romero P. (1) Delgado Rodriguez ${ }^{(1)}$. \\ (1) Universidad de las Fuerzas Armadas - ESPE. Departamento de Ciencias de la \\ Vida y de la Agricultura, Centro de Nanociencia y Nanotecnología (CENCINAT). \\ Sangolquí - Ecuador, vaaguirre@espe.edu.ec, apgavilanes@espe.edu.ec, \\ piromero@espe.edu.ec, vadelgado@espe.edu.ec
}

Recibido: noviembre, 2019 Aceptado: diciembre, 2019

\section{RESUMEN}

Este trabajo de investigación inició de la pregunta de si se produce inhibición en el crecimiento del hongo patógeno Botrytis fabae con el uso de liposomas y nanopartículas de azufre. El objetivo fue explicar cómo utilizando concentraciones $0,001 \mathrm{M}$ de nanopartículas de azufre encapsulado en liposomas de fosfatidilcolina en mezclas de limoneno y octanol, actúan sobre el cultivo in vitro del hongo Botrytis fabae. Durante esta investigación se obtuvieron nanopartículas de azufre. Se demostró que la fosfatidilcolina abarcaba azufre y forma liposomas. Así mismo se identificó el hongo Botrytis fabae por el cultivo in vitro. La impregnación de los discos se realizó inmediatamente en la siembra del hongo y se detectó la inhibición completa por el componente octanol- fosfatidilcolina con nanoparticulas de azufre usados en la síntesis de los liposomas, con una sensibilidad alta de un radio de $45 \mathrm{~mm}$ y sin efecto por los liposomas de fosfatidilcolina con limoneno. Comparado con el tratamiento del producto comercial carbendazim, el cual formó un halo de inhibición de $17 \mathrm{~mm}$ de radio que corresponde a una sensibilidad intermedia. Se utilizó un diseño experimental completamente al azar (DCA) y el método de sensibilidad en disco.

Palabras claves: Liposomas. Azufre. Nanopartículas. Botrytis fabae. Vicia faba. Fosfatidilcolina.

\section{ABSTRACT}

This research work initiated the question of whether inhibition in the growth of the pathogenic fungus Botrytis fabae occurs with the use of sulfur liposomes and nanoparticles. The objective was to explain how using concentrations of $0.001 \mathrm{M}$ sulfur nanoparticles encapsulated in phosphatidylcholine liposomes in mixtures of 
limonene and octanol, act on the in vitro culture of the fungus Botrytis fabae. During this investigation sulfur nanoparticles were obtained. Phosphatidylcholine was shown to encompass sulfur and form liposomes. Likewise, the Botrytis fabae fungus was identified by in vitro culture. The impregnation of the discs was performed immediately in the seeding of the fungus and the complete inhibition by the octanol-phosphatidylcholine component was detected with sulfur nanoparticles used in the synthesis of the liposomes, with a high sensitivity of a radius of $45 \mathrm{~mm}$ and without effect by liposomes of phosphatidylcholine with limonene. Compared to the treatment of the commercial product carbendazim, which formed an inhibition halo of $17 \mathrm{~mm}$ radius corresponding to an intermediate sensitivity. A completely randomized experimental design (DCA) and disc sensitivity method were used.

Keywords: Liposomes. Sulfur. Nanoparticles. Botrytis fabae. Vicia faba. Phosphatidylcholine

\section{INTRODUCCIÓN}

La planta del haba, Vicia faba, originaria de la cuenca mediterránea e introducida en el país, es importante en la alimentación de la población ecuatoriana (FAO, 2016), con impacto en la producción económica equivalente al $10 \%$ producto interno bruto (Lucero, 2014), siendo afectada por un hongo patógeno conocido como Botrytis fabae y Botrytis cinerea, responsables de la enfermedad que provoca la pudrición de las hojas, tallos, granos y vainas (SYNGENTA, S.f) El daño a nivel de las hojas se caracteriza por unas manchas de color café rojizo también conocida como mancha chocolate (Lucero, 2014). Entre las alternativas de tratamiento que se suministra es el manejo de agroquímicos, cuyos principios activos para combatirlos son el tretracloroisoftalonitrito, dicarboxilamida y procymidone, carbendazim y benzimidazol, benomil (Peralta, 1998). La empresa Bioquirama soluciones de origen colombiana ha desarrollado pruebas de sensibilidad en disco con algunos principios activos contra Botrytis $s p$ como el carbendazim y reporta baja sensibilidad a este principio activo (Bioquirama, S.f) En general deben ser utilizados con precaución. Para el caso de tretracloroisoftalonitrito es toxico e irritante al ser inhalado y en contacto con los ojos, tiene efectos letales para los peces y hay poca evidencia de ser teratógeno (Ecuaquimica, S.f)

Por otra parte la lecitina de soya o fosfatidilcolina es obtenida de la planta Glicyne max, muy rica en fosfatidil colina, fosfatidil serina, fosfatidil inositol, utilizada en la industria alimenticia, farmacéutica (Moreno, 2018), por varias propiedades benéficas tales como su contenido en ácidos grasos omega linoleico y linolénico (Tamargo et al., 2011). Son sus fosfolípidos los que están en capacidad de dar lugar a la formación de estructuras membranosas artificiales que tienen un bicapa lipídica y en su interior moldean un compartimento acuoso idóneo para albergar principios activos. Se ha planteado como problema que el azufre es un conocido no metal que tiene propiedades antimicóticas y hay otros elementos como la plata con capacidades parecidas. Para poder utilizarlo en una escala nanométrica se lo hace reaccionar de manera que se sintetiza nanopartículas de 
azufre (Robles, et al., 2019), existe evidencia que el azufre es tóxico junto con alcaloides contra F. oxysporum (Argüelles, 2019). Luego el azufre es introducido y transportado en liposomas de fosfolípidos (Berg, Stryer, \& Tymoczko, 2007). La lecitina de soya en mezclas con octanol y un derivado sintético de limoneno se utilizan en la preparación, debido a que se requiere de solventes orgánicos (Lopez, s/f). Posteriormente de conocer que efectivamente existen liposomas que envuelven azufre se demuestra su efecto en un cultivo in vitro del hongo aislado de Botrytis fabae (Soria, 2015).

El objetivos general de este proyecto es determinar la acción que produce concentraciones de nanopartículas de azufre encapsulado en liposomas de fosfatidilcolina, aplicado al cultivo in vitro del hongo Botrytis fabae. Obtener las nanopartículas de azufre de tamaño y características adecuadas. Demostrar el encapsulamiento de las nanopartículas de azufre en los liposoma de fosfatidilcolina. Aislar e identificar el hongo Botrytis fabae cultivado in vitro. Constatar las consecuencias de la aplicación de los liposomas de azufre en cultivo in vitro del hongo.

\section{METODOLOGÍA}

\subsection{Preparación de nanopartículas de azufre}

En un matraz erlenmeyer se añadió un tampón formado de acetato de sodio y ácido acético a una concentración $0,001 \mathrm{M}$, utilizando $1 \mathrm{~mL}$ de este preparado a un $\mathrm{pH}$ de 4 . En la solución anterior se juntó $1 \mathrm{~mL}$ de ácido clorhídrico al $1 \%$. Se agregó finalmente $23 \mathrm{~mL}$ de tiosulfato de sodio 0,001 $\mathrm{M}$, pentahidratado. Se dejó 1 hora de tiempo para que se produzca la reacción y libere nanopartículas de azufre. La medida del $\mathrm{pH}$ de la mezcla mostraba un valor de 3.7.

\subsection{Preparación de la muestra para la observación al microscopio electrónico TEM:}

En un ependor se lo lleno con la solución de nanoparticulas de azufre preparado a partir de tiosulfato de sodio $0,001 \mathrm{M}$. En otro ependor lo llenamos de los liposomas de azufre/octanol-lecitina (S/O.L) y octanol-lecitina/azufre (O.L/S) que han sido incorporados con las nanopartículas de azufre para ser observados al microscopio electrónico de barrido TEM. En un ependor adicional lo llenamos con la solución de limoneno-lecitina de soya/ nanoparticulas de azufre (L.L/S) y S/L.L. Así se envía para que sean analizadas en TEM.

\subsection{Preparación de liposomas de octanol}

Basado en el método de obtención de liposomas unilaminares o método de REV (Ortiz, 2015), se pesó lecitina de soya comestible. Se añadió a un vaso con octanol y se disolvió, la mezcla obtenida fue transparente de color amarillento al 1,2 \%. Luego en un balón contendrá la mezcla de octanol-lecitina mas solución de tiosulfato de sodio en una relación entre nanopartículas de azufre /octanol- 
lecitina de soya (S/O.L). En el otro balón de solución de nanoparticulas de azufre en solución acuosa se mezcla octanol - lecitina (O.L/S).

\subsection{Preparación de liposomas de limoneno}

Se pesó la lecitina de soya comestible, se añadió a un vaso con limoneno y se lo disolvió, la mezcla obtenida fue transparente de color amarillento al 1,2\%. Luego en un balón contuvo la mezcla de limoneno-lecitina mas solución de tiosulfato de sodio en una relación entre nanopartículas de azufre /limonenolecitina de soya (S/L.L). En el otro balón de solución de nanoparticulas de azufre en solución acuosa se mezcló limoneno -lecitina/azufre (L.L/S).

Las muestras de nanopartículas de azufre y liposomas se enviaron las preparaciones para que sean analizadas en TEM.

\subsection{Crecimiento in vitro del hongo Botrytis fabae}

Se sembró Botrytis fabae a partir de un medio de agar papa dextrosa (PDA), donde fue previamente aislado e identificado por la observación al microscopio óptico.

Al mismo tiempo del medio de cultivo de $B$. fabae antes mencionado se lo replico en 39 cajas Petri de PDA. En pruebas exploratorias el hongo de Botrytis fabae creció del cuarto al séptimo día de incubación.

\subsection{Probar la sensibilidad del hongo frente a los liposomas}

Se utilizó el método Kirby-Bauer en el que se tomó una porción de muestra del cultivo de Botrytis fabae con un hisopo y este se depositó en agua destilada, se añadió los discos impregnados con los componentes por separado que conforman los liposomas y sus mezclas inmediatamente después efectuar la siembra de Botrytis fabae. El proceso se produjo en condiciones de esterilidad. La tabla 1 siguiente expresa la interpretación necesaria.

Tabla 1

\begin{tabular}{|l|l|}
\hline \multicolumn{2}{|l|}{ Tabla interpretativa de la prueba de sensibilidad (Técnica de KirbyBauer) } \\
\hline Clasificación de interpretación & Interpretación \\
\hline Positivo & $\begin{array}{l}\text { Si el radio del halo es mayor a } 9 \mathrm{~mm} \\
\text { (diámetro mayor a } 18 \mathrm{~mm} \text { ) }\end{array}$ \\
\hline Actividad intermedia & $\begin{array}{l}\text { Si el radio del halo es de } 6-9 \mathrm{~mm} \\
\text { (diámetro entre 12-18 } \mathrm{mm} \text { ) }\end{array}$ \\
\hline Negativo (sin actividad) & $\begin{array}{l}\text { Si el radio del halo es inferior a } 6 \mathrm{~mm} \\
\text { (diámetro inferior a } 12 \mathrm{~mm} \text { ) }\end{array}$ \\
\hline
\end{tabular}

Fuente: Rodríguez Cavallini Evelyn et al., 2005

\subsection{Diseño experimental}

El método que se empleó fue el (DCA). Es una investigación explicativa, que analizo el efecto del azufre nanoencapsulado en vesículas lipídicas frente a un hongo Botrytis fabae. Las sustancias usadas en los tratamientos se describen en la tabla 3 , tomando de manera constante veinte microlitros de cada uno. 
Se planteó como hipótesis nula que todos los tratamientos producen inhibición del crecimiento de Botrytis fabae. El paquete estadístico utilizado fue el infostat que permitió la implementación de las pruebas de análisis de varianza y de comparaciones entre tratamientos con la prueba estadística de Duncan.

\section{RESULTADOS}

\subsection{Síntesis de las nanopartículas de azufre tamponado}

Se desarrolló la síntesis de nanopartículas de azufre utilizando el tiosulfato de sodio, con ácido clorhídrico y un tampón. Se analizaron las muestras de las preparaciones a través de DLS y TEM donde se verifico el tamaño de partícula de 11 nanómetros. Se obtuvo las imágenes de las nanopartículas de azufre, como presenta la figura 1.

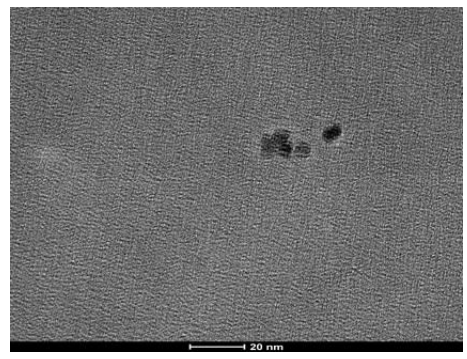

Figura 1: El azufre se observa de color negro. Los diámetros de 11 nanómetros. Imagen tomada por TEM

\subsection{Síntesis de liposomas a partir de lecitina de soya y octanol con nanopartículas de azufre}

El análisis TEM (Microscopía electrónica de transmisión), permito distinguir que a partir de la lecitina de soya comercial se sintetizo las estructuras artificiales de liposomas que han pasado por un proceso de sonicación y cuyo tamaño fue de 30 nanómetros incorporando nanopartículas de azufre. Se divisa como unilamelares y se notan en las imágenes de la figura 2.

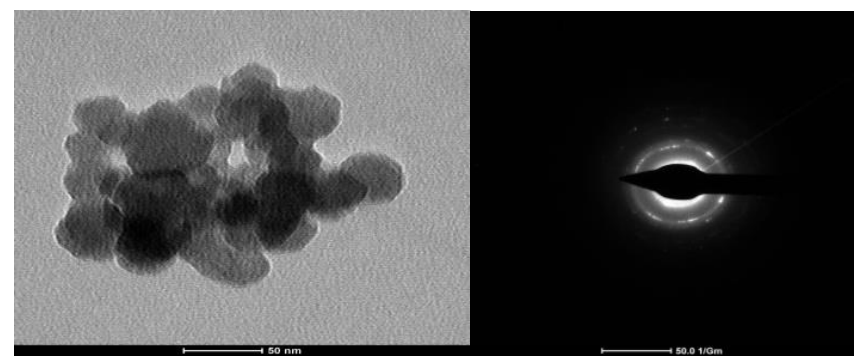

Figura 2: liposoma de lecitina de soya. Se muestra estructuras esféricas de unos treinta nanómetros, característico de los liposomas 


\subsection{Síntesis de liposomas a partir de lecitina de soya y el sintético de limoneno con nanopartículas de azufre.}

Al analizar con TEM la imagen presento estructuras esféricas constituidas por lecitina de soya utilizando el sintético de limoneno como disolvente. Los tamaños oscilan entre 17 a 30 nanómetros que es captado en las imágenes de la figura 3.

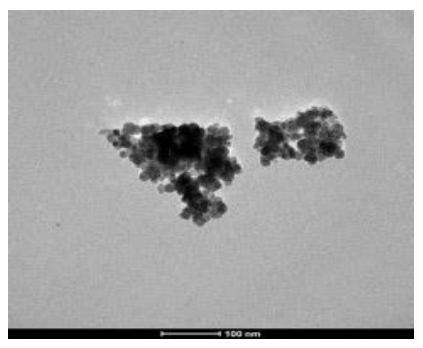

Figura 3: Liposomas de lecitina de soya. Esta imagen muestra a una estructura esférica.

\subsection{Análisis del tamaño de las estructuras de liposomas de lecitina} de soya con octanol y sintético de limoneno usando DLS (Dispersión de luz dinámica).

El histograma presento un tamaño promedios de 16,2 nanómetros. El histograma se elaboró en función del estudio de dieciséis imágenes seleccionadas y sus resultados son expuestos en la figura 4.

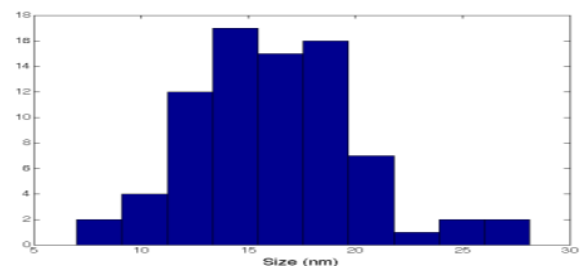

a)

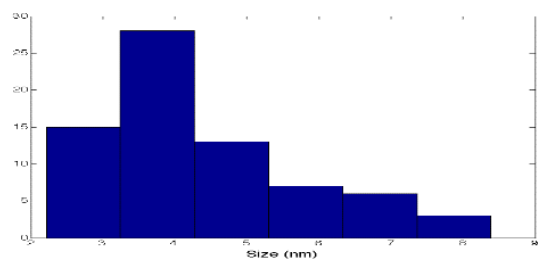

b)

Figura 4: a) Histograma por DLS de liposomas donde se observan los siguientes resultados: el promedio de los SO-L: 4,4nm std de los SO-L: 1,4nm; liposoma 2: promedio $=17,9 \mathrm{~nm}, \mathrm{std}=3,9 \mathrm{n}$; liposoma 3: promedio $=15,0 \mathrm{~nm}, \mathrm{std}=3,6 \mathrm{~nm}$. b) Histograma de liposomas donde se observa: liposoma 2+3: promedio=16,2nm, $\mathrm{std}=3,9 \mathrm{~nm}$

\subsection{Crecimiento in vitro del hongo Botrytis fabae}

A los siete días luego de la siembra de Botrytis fabae se produjo un notable desarrollo del hongo. La colonia macroscópica es miceliar blanquecina hacia el exterior y negruzca hacia el interior. Son colonias inicialmente de color café claro y con el tiempo se vuelven parduzcas. La observación al microscopio óptico de una muestra del cultivo permitió diferenciar las estructuras típicas de 
Botrytis fabae donde se observa el micelio, los conidióforos y conidias y se pudo evidenciar en la imagen de la figura 5 y 6.

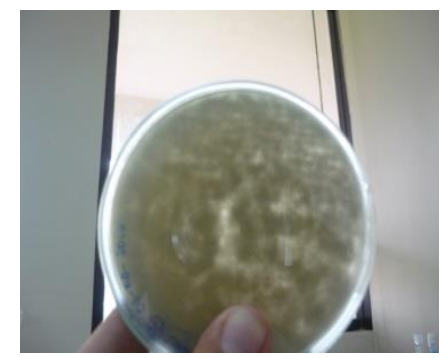

Figura 5: Crecimiento in vitro de Botrytis fabae en medio PDA

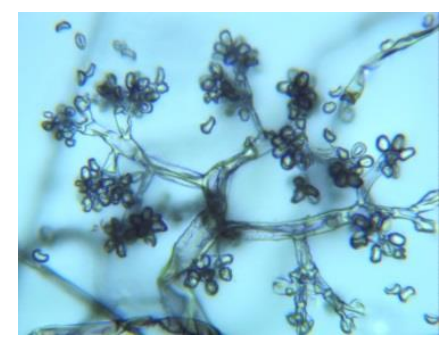

Figura 6: Botrytis fabae observado con 40x donde se

Identifica el micelio, los conidióforos y conidias

\subsection{Sensibilidad del hongo frente a los liposomas}

Se realizaron ensayos de trece tratamientos y tres repeticiones utilizando los componentes que forman los liposomas por separado y sus respectivas mezclas aplicando (DCA), siendo la variable de respuesta la acción sobre el cultivo del hongo Botrytis fabae revelado en las imágenes 1, 2, 3, 4.

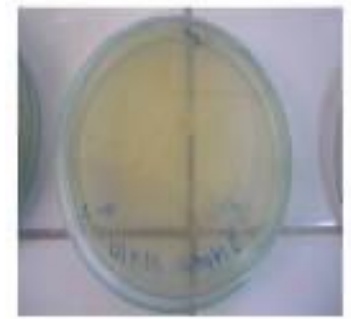

1.

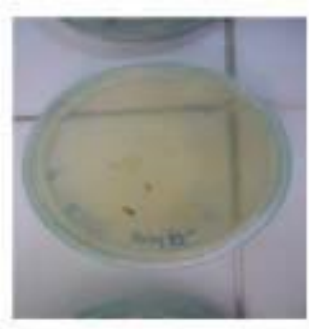

2

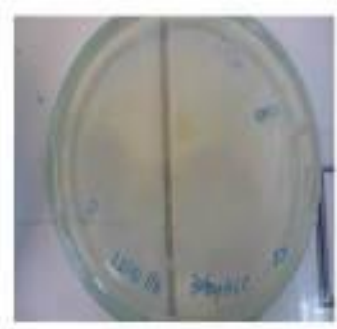

3.

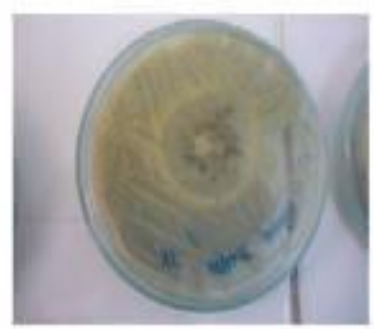

4.

Figura 7: Fotografías del cultivo in vitro de Botrytis fabae. 1) Es la inhibición producida por el tratamiento cuatro de octanol donde el radio de inhibición es de $45 \mathrm{~mm}$ de sensibilidad positiva. 2) Es el tratamiento de la mezcla octanol lecitina 
cuya sensibilidad es positiva con un radio de $45 \mathrm{~mm}$. 3) Es el tratamiento ocho de liposomas de mezcla de octanol lecitina y 20 uL solución de azufre elemental produciendo una sensibilidad positiva de $45 \mathrm{~mm}$ de radio. 4) Es el tratamiento doce usando el producto carbendazim y obteniendo una sensibilidad intermedia de $17 \mathrm{~mm}$ de radio.

La siguiente tabla 2 arroja los datos del análisis de varianza usando el programa estadístico infostat.

Tabla 2

Análisis de la varianza de los tratamientos y respuestas en el desarrollo del cultivo in vitro de Botrytis fabae

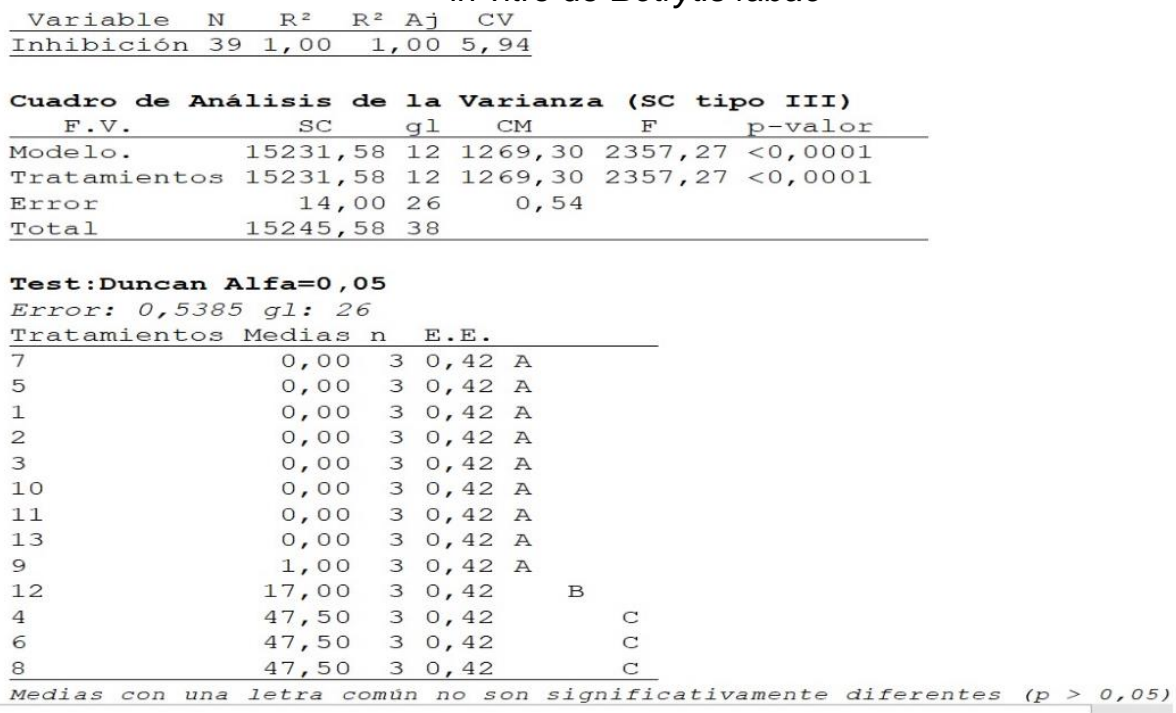

El $p$ valor es 0,0001 para los tratamientos siendo menor a $p$ - valor 0,05 por lo que se rechazó la hipótesis nula y se aceptó la hipótesis alternativa de que si existe diferencias significativas entre los tratamientos. El coeficiente de variación de $5,94 \%$ es una buena medida al ser un valor bajo y encontrarse hasta el $10 \%$ y quiere decir que en el ensayo los datos de respuesta obtenidos muestran mayor homogeneidad en los valores. Conforme al análisis de varianza los tratamientos \#4 de octanol, \#6 mezcla de octanol-lecitina de soya, \#8 mezcla de octanol -lecitina y 20 uL solución de nanopartículas de azufre, con una respuesta de halo de 45,7 $\mathrm{mm}$ de radio que es prácticamente una inhibición total en crecimiento del hongo Botrytis fabae son calificados con la letra $\mathrm{C}$ y tienen una sensibilidad positiva. El tratamiento 12 compuesto de carbendazim con $0.0625 \mathrm{mg}$ y tomando $20 \mathrm{uL}$, provoca una respuesta de sensibilidad intermedia con un radio de inhibición de 17 $\mathrm{mm}$ y es el que normalmente se usa como tratamiento del hongo Botrytis fabae y se lo representa con la letra $B$. Los tratamientos $1,3,2,5,9,13,11$, 10, son de sensibilidad negativa como por ejemplo la solución de tiosulfato de sodio $0,001 \mathrm{M}$ o el ácido clorhídrico al $1 \%$ en los que hay ausencia de formación de halo y gran crecimiento del hongo Botrytis fabae y es representado por la letra A. Observar los resultados en las tablas 2 y 3 . 
Tabla 3

Resumen de la respuesta de los tratamientos y los radios de inhibición provocados en el desarrollo de Botrytis fabae

\begin{tabular}{|c|c|c|c|c|c|}
\hline \multirow[t]{2}{*}{ Tratamiento } & \multirow[t]{2}{*}{ Composición } & \multicolumn{3}{|c|}{$\begin{array}{l}\text { Repeticiones y medida del radio de } \\
\text { inhibición en milímetros }\end{array}$} & \multirow[t]{2}{*}{ Sensibilidad } \\
\hline & & I & II & III & \\
\hline 1 & Solución de tiosulfato de sodio $0.001 \mathrm{M}$ & 0 & 0 & 0 & Negativo \\
\hline 2 & Ácido clorhidrico al $1 \%$ & 0 & 0 & 0 & Negativo \\
\hline 3 & Solucion de acidos acético $0.001 \mathrm{M}$ & 0 & 0 & 0 & Negativo \\
\hline 4 & Octanol & 47.5 & 47.5 & 47.5 & Positivo \\
\hline 5 & Sintético de limoneno & 0 & 0 & 0 & Negativo \\
\hline 6 & Mezcla de octanol -lecitina de soya & 47.5 & 47.5 & 47.5 & Positivo \\
\hline 7 & $\begin{array}{l}\text { Mezcla del sintético de limoneno y } \\
\text { lecitina de soya }\end{array}$ & 0 & 0 & 0 & Negativo \\
\hline 8 & $\begin{array}{l}\text { Mezcla de octanol lecitina }+20 \mathrm{uL} \\
\text { solucion de nanoparticulas de azufre. }\end{array}$ & 47.5 & 47.5 & 47.5 & Positivo \\
\hline 9 & $\begin{array}{l}\text { Mezcla octanol lecitina } 20 \text { uL en } \\
\text { solución de nanoparticulas de azufre.. }\end{array}$ & 3 & 0 & 0 & Negativo \\
\hline 10 & $\begin{array}{l}\text { Mezcla de sintético de limoneno y } \\
\text { lecitina de soya con } 20 \text { uL solucion de } \\
\text { nanoparticulas de azufre. }\end{array}$ & 0 & 0 & 0 & Negativo \\
\hline 11 & $\begin{array}{l}\text { Mezcla de sintético de limoneno y } \\
\text { lecitina de soya en solución de } \\
\text { nanoparticulas de azufre. }\end{array}$ & 0 & 0 & 0 & Negativo \\
\hline 12 & Solución carbendazim & 17 & 19 & 15 & Intermedio \\
\hline 13 & Agua destilada & 0 & 0 & 0 & Control \\
\hline
\end{tabular}

Fuente: El autor

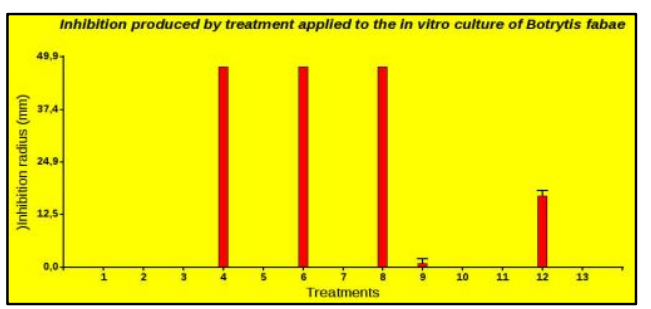

Figura 8. Se observa los tratamientos los cuales han provocado una sensibilidad positiva inhibiendo el desarrollo de Botrytis fabae en las barras de color rojo. Los demás tratamientos son de sensibilidad negativa.

Nota: Los tratamientos se designan con las letras T y el número correspondiente.

\section{DISCUSIÓN}

El tratamiento de los liposomas sintetizados de la mezcla octanol-lecitina de soya y nanopartículas de azufre en concentración $0.001 \mathrm{M}$, utilizando veinte microlitros son altamente efectivas contra el hongo Botrytis fabae debido a que en su síntesis se utiliza el octanol. 
El octanol tiene el propósito de disolver la lecitina de soya y es un componente principal de la mezcla para la síntesis de los liposomas, siendo el responsable de ese efecto de impedir el desarrollo de Botrytis fabae, se deduce porque ocurre el mismo hecho cuando se utiliza $20 \mathrm{uL}$ del octanol exclusivamente, cuyo nivel de aparición del radio de inhibición es idéntico para ambos tratamientos, con un valor de cuarenta y cinco milímetros. Existe una patente declarada en organización mundial de propiedad intelectual WIPO donde se indica la numero 291. (MXPA/a/2003/003648) referida a una mezcla que contiene octanol y es mencionada como formulaciones auxiliares agroquímicas para plagas (Patent Núm. PA/a/2003/003648, 2005).

Otro trabajo propone la utilización de lecitina de soya empleando el alcohol etílico como disolvente para formar liposomas vacíos (Gonzalez, 2014). En el presente estudio cuando se probó con alcohol etílico el nivel de disolución fue poco eficiente debido a que se comporta por su polaridad semejante al agua (Fernández, s/f).

En otro estudio utilizan lecitina para la formación de liposomas con el propósito de englobar el hierro II congelando y descongelando la suspensión lecitina, en nuestro método se logra la formación sin someter a congelación a la suspensión de fosfoglicérido (Haguer, 1996).

La evidencia vislumbra que los liposomas formados por el sintético de limoneno, lecitina de soya y nanopartículas de azufre en concentración $0.001 \mathrm{M}$, no tienen acción inhibitoria en el crecimiento del hongo. El limoneno es un tipo de terpeno y estos terpenos son degradados por Botrytis cinerea en racimos de uva hasta compuestos que han disminuido en sus propiedades aromáticas y así avanzar en su ataque (Togores, s/f). Al ser variedades muy cercanas con Botrytis fabae podría ser la razón de nula actividad inhibitoria de su desarrollo.

La hipótesis de que al menos un tratamiento utilizando liposomas es significativo frente al crecimiento de Botrytitis fabae se adopta en el trabajo. Es interesante por otra parte que el tamaño de los liposomas fluctuó entre 17 a 25 nanómetros y se los aprecia como unilaminares coincidiendo con las dimensiones propuestas en otro estudio de 25 a $50 \mathrm{~nm}$ cuando en la técnica se ha sometido básicamente a ultrasonicación (Lopez, s/f).

Se sintetizan las nanopartículas de azufre a partir del tiosulfato de sodio pentahidratado al valerse de un amortiguador, arrojando un tamaño promedio de 11 nanómetros. Otro trabajo logra utilizar el azufre cero, pero a partir sulfuro de hidrógeno para que sea de mayor biodisponibilidad en seres humanos (Romanillos, 2013).

La sustancia de elección para combatir al hongo Botritis fabae el carbendazim tiene menor eficacia que la sustancia octanol cuando se lo usa aisladamente y en mezcla de la síntesis de liposomas. El radio de inhibición del carbendazim de $17 \mathrm{~mm}$ es inferior al de octanol y la mezcla S/O.L de $45 \mathrm{~mm}$. En un estudio realizado del carbendazim frente a Botrytis cinerea en sus resultados encontraron una sensibilidad intermedia con una dosis de $100 \mathrm{mg} / \mathrm{litro}$ (Zealand, 1985). 
Las sustancias como el ácido clorhídrico, el ácido acético al ser probado su efecto en el cultivo de Botrytis fabae se produce una sensibilidad negativa. Se argumenta en este sentido que el hongo crece adecuadamente en $\mathrm{pH}$ ácido para luego aprovechar las sustancias ácidas en su propio desarrollo y modificar el pH hasta valores superiores a 3.5. Un estudio en Botrytis cinerea plantea que crece y germina los conidios perfectamente en pH superiores a 3.7 (Martinez \& Moreno, 2008).

\section{CONCLUSIONES}

Se pudo probar la obtención nanopartículas de azufre a partir de tiosulfato de sodio en concentración $0.001 \mathrm{M}$, evidenciando su presencia por TEM (Microscopía electrónica de transmisión), con tamaños de $11 \mathrm{~nm}$ medidos con dispersión de luz dinámica (DLS).

Se sintetizo liposomas utilizando lecitina de soya comestible, cuyas dimensiones oscilan en promedio de 16,2 nanómetros observados por TEM, empleando dos sustancias de diferente naturaleza, siendo el octanol y un derivado sintético de limoneno, parte de sus síntesis.

Se aisló Botrytis fabae in vitro y con un DCA se aceptó la hipótesis alternativa de que si existe diferencias significativas entre los tratamientos. El coeficiente de variación fue de 5,94\%. Concluyendo que la mayor inhibición sobre el crecimiento de Botrytis fabae lo provocan los tratamientos 4, 6 y 8 de, octanol, octanol-lecitina de soya y la mezcla octanol-lecitina de soya -solución de nanopartículas de azufre que forman liposomas respectivamente. Lo sigue el tratamiento del carbendazim producto comercial con un halo de inhibición de sensibilidad intermedia.

Es notable que cuando los principios activos impregnados en los discos son aplicadas una vez que el hongo Botrytis fabae ha desarrollado hasta el día doce, la acción inhibitoria en el crecimiento es nula para todos los tratamientos.

\section{REFERENCIAS}

1. Argüelles, Iván. (2019). Actividad antifúngica de Pseudognaphalium luteoalbum (L.) Hilliard \& B.L Burtt. Institución de enseñanza e investigación en Ciencias Agrícolas. Tesis de grado. México. 2019. Disponible en https://www.researchgate.net/publication/334191318_Actividad_Antifungic a_de_Pseudognaphalium_luteoalbum_L_Hilliard_BL_Burtt

2. Bioquirama, "Pruebas_Antagonismo.pdf", S.f. [En línea]. Disponible en: http://www.bioquirama.com/pdf/Pruebas_Antagonismo.pdf. [Consultado: 21-ago-2017], pp.29-34

3. D. Lucero, "Determinación del efecto del elicitor ácido acetilsalicílico sobre el control de mancha chocolate (Botrytis fabae L.), en el cultivo de haba (Vicia faba L.)", Tesis de pregrado, Universidad Politécnica Estatal del Carchi, Ecuador, 2014. 
4. E. Peralta, "Manual agrícola de leguminosas: cultivos y costos de producción". INIAP, 1998.

5. Ecuaquimica, "Daconil Ultrex GDA". Edifarm, S.f, pp. 1-2T. Tamargo, H. Herrera, B.-A. Bello-Alarcón, C. Cuéllar, G.-R. González-Rodríguez, y H. \& S.-G. H. \& Sierra-González, "Obtencion de fosfolipidos a partir de la lecitina de soya (Glicine max L), para usos biomédicos", vol. 23(3), 5+, sep. 2011.

6. FAO. "Las legumbres". 2016.

7. Fernández, "Estabilidad coloidal de nanoestructuras liposómicas". Tesis Doctoral, Universidad de Santiago de Compostela. España, 2007.

8. G. Romanillos, "Preparación y composiciones de azufre con valencia cero. altamente bio-disponibles y sus usos WO2013055199A1 - Google Patents", 2013. [En línea]. Disponible en: https://patents.google.com/patent/WO2013055199A1/es?q=Preparaci\%C3 $\% B 3 n+y \& q=$ composici\%C3\%B3n+de+azufre \&q=con\&q=valencia\&q=cero\& $q=a l t a m e n t e \& q=$ bio-disponible+y\&q=sus+usos. [Consultado: 23-ago2017].

9. Haguer, "Liposomas que contienen hierro (ii) biodisponible y procedimiento para obtenerlos.", 1996. [En línea]. Disponible en: https://patents.google.com/patent/ES2083921B1/esq=Liposomas+que+co ntienen\&q=hierro\&q=(II)\&q=biodisponible+y\&q=procedimiento+para\&q=0b tenerlos. [Consultado: 23-ago-2017].

10. J. H. Togores, "La calidad del vino desde el viñedo". Mundi-Prensa Libros. España, 2006, pp. 224-226

11. J. M. Berg, L. Stryer, y J. L. Tymoczko, Bioquímica. España. Reverte, 2007, pp. 332-335.Lopez, "Liposomas de Pc-Peg-Travaprost para el tratamiento sostenido de la presión intraocular en la enfermedad de glaucoma", Trabajo fin de máster inédito, Centro de Investigación en Materiales Avanzados, S.f.

12. J. Stewart, "Composición auxiliar para formulaciones agroquímicas y usos de la misma", PA/a/2003/003648, Mayo, 2005.

13. Lopez, "Liposomas de Pc-Peg-Travaprost para el tratamiento sostenido de la presión intraocular en la enfermedad de glaucoma", Trabajo fin de máster inédito, Centro de Investigación en Materiales Avanzados, S.f.

14. M. Martinez y Z. Moreno, "Estandarización de una metodología para la evaluación de eficacia de productos para la protección de cultivo (PPC) preventivos para el control de Botrytis $s p$ en condiciones semicontroladas". Pontificia Universidad Javeriana. Facultad de Ciencias Carrera de Microbiología Industrial, D.C, Bogotá, D.C, 2008.

15. Moreno, S. G. (2018). Depleting Macrophages In Vivo with ClodronateLiposomes. En G. Rousselet (Ed.), Macrophages: Methods and Protocols (pp. 259-262). https://doi.org/10.1007/978-1-4939-7837-3_23

16. M. Ramirez, "Tendencias de innovación en la ingeniería de alimentos". Omnia Science, 2015. pp. 226-230.

17. P. Gonzalez, "Liposomas vacíos como adyuvante de diferentes principios activos, administrados independientemente y en su forma galénica convencional ES2442450B1 - Google Patents", 2014. [En línea]. Disponible

en: https://patents.google.com/patent/ES2442450B1/es?q=Liposomas\&q=vac $\%$ C3\%ADos\&q=como+adyuvante+de+diferentes\&q=principios+activos $\% 2$ 
$c \& q=a d m i n i s t r a d o s \& q=i n d e p e n d i e n t e m e n t e \& q=y \& q=e n+s u+f o r m a \& q=g a l$ \%C3\%A9nica\&q=convencional. [Consultado: 23-ago-2017].

18. R.E Beever. New Zealand Journal of Agricultural Research. The Royal Society of New Zealand, 1985. pp. 291-292

19. Robles, Marissa. (2019). Sinergia entre las plantas medicinales y la nanotecnología. Doctorado institucional en ingeniería y ciencia de materiales. UASLP. México. 2019. Recuperado de http://www.uaslp.mx/ComunicacionSocial/Documents/Divulgacion/Revista/ Dieciseis/239/239-05.pdf

20. Soria, "Caracterización morfológica de hongos fitopatógenos en el cultivo de haba (Vicia faba L.). Sector la Urbina, cantón Pillaro, Tungurahua 2015”, Título de pregrado. Universidad Técnica de Cotopaxi, Ecuador, 2015.

21. SYNGENTA, "Biología de Botrytis y novedoso enfoque del control químico para alcanzar alta eficacia de productos químicos usados para su control". S.f, pp. 1-2.

22. T. Tamargo, H. Herrera, B.-A. Bello-Alarcón, C. Cuéllar, G.-R. GonzálezRodríguez, y H. \& S.-G. H. \& Sierra-González, "Obtencion de fosfolipidos a partir de la lecitina de soya (Glicine max L), para usos biomédicos", vol. 23(3), 5+, sep. 2011. 